\title{
Effect of physical and chemical parameters on water treatment plant effluent quality (particle count and particle size)
}

\author{
A. Torabian ${ }^{1}$, A. Hesam Hasani ${ }^{1}$ \& A. R. Mehrabadi ${ }^{2}$ \\ ${ }^{I}$ Faculty of Environment, Azad University Research and Science, \\ Tehran, Iran \\ ${ }^{2}$ Power and Water University of Technology, Tehran, Iran
}

\begin{abstract}
The city of Tehran uses surface water to supply drinking water to a population of more than 10 million people via five large water treatment plants. Tehran's water treatment plants consist of pre-treatment, coagulation, flocculation, filtration and disinfection units (conventional treatment). The plants' effluent quality is in compliance with WHO standards. Drinking water standards these days are getting more stringent because of our knowledge about pollutants and the development in measurement instruments. Meeting new drinking water standards that will be enforced by regulatory agencies in the future is a challenge to the water industry. Removal of micro organisms such as Giardia, Cryptosporidium, $\mathrm{DBD}, \mathrm{TOC}$ and particle size and particle count are playing a more important role in new standards.

In this experimental study a conventional pilot plant was designed, built and used during a period of six months to study the effect of type and dose of coagulant, filtration rate on particle count and particle size of treated water. Particle size and count is a surrogate measure for the removal of pathogens such as bacteria, viruses, Giardia, Lambia, and Cryptosporidium.

The results of this study indicated that the filtration rate and type of coagulant dosage has more effect than the other operational parameters on overall effluent quality and on particle size and count.
\end{abstract}

Keywords: drinking water quality standards, particle size and count. 


\section{Introduction}

Water quality standards have undergone intense scrutiny and evolution in the U.S., Canada, and Europe in recent years, based on a growing body of knowledge of possible contaminates in water supplies and their potential health significance [1]. Removal of micro organisms such as Giardia, Cryptosporidium, DBD, TOC and particle size and particle count are playing a more important role in new standards [2].

The concept of using particle counters to monitor and control the water treatment plants' performance is relatively new. Conventional water treatment relies upon turbidity measurements to determine how well filters are performing and while turbidity measurements are useful, the information received from a turbidity meter is limited. A turbidity meter can tell you how "cloudy" the water is, but it can not tell you whether the "cloudiness" is caused by lots of small particles, a few large particles or any combination of the two. A particle counter can tell you how many particles are passing through a filter and what size they are. Particle counters are there for more effective tools for monitoring filtration performance than turbidity meters $[3,4]$.

It was suggested that 20 particles $/ \mathrm{ml}$ could reasonably minimize the risk of Giardia and Cryptosporidium [4, 5].

Turbidity and particle counting results are related since both are measures of water clarity [6]. Particle counting data have been correlated to turbidity directly as count of data source water turbidity ranging from 0.6 to $7.4 \mathrm{NTU}$ corresponded to particle counts ( $\mathrm{NP} \geq 2.0 \mu \mathrm{m} / \mathrm{ml}$ ) ranging from 7800 to 30000 particles /ml [7].

The relationship between particle counting results and cyst or oocyst removal remains controversial [7]. Lechavallier and Norton [8] showed correlation coefficients of near 0.8 between log removal of naturally occurring Giardia and Cryptosporidium and log removal of turbidity [8, 9]. Even stronger correlation's between cyst removal and log removal of particles greater that 5 $\mu \mathrm{m}$ were reported [8], Patania et al. [10] however, found that removal of Cryptosporidium and Giardia by filtration were poorly correlated to both turbidity and particle counts turbidity, and particle removal by filtration were reported to be consistently lower than organism removal. It was concluded that the use of particle removal as a surrogate for cyst or oocyst removal would underestimate actual removal of Giardia or Cryptosporidium. Although the use of particle counting as a surrogate measure of Giardia or Cryptosporidium removal for regulatory compliance may be controversial, the fundamental value of particle counting for drinking water treatment performance monitoring remains unchallenged [7].

The objective of this research work is to study the effect of operational parameters in water treatment plants on the particle size and particle count of the effluent in order to optimize the efforts in operation for meeting the standards and indicating which parameters have the most effective influence on the effluent particle size and count which can be relative to Giardia and Cryptosporidium cyst and the actual quality of the effluent. 


\section{Materials and methods}

\subsection{Pilot configuration}

A laboratory pilot was used to conduct the experiments in this study which is shown in figure 1 . The pilot consisted of a raw water supplying unit, coagulation and flocculation units, distribution basin and flow measuring units, filtration units and a backwash system. The raw water supplying unit consists of one stoke of turbidity equipped with a mixer and an adjustable dosing pump, and also a constant height storage tank equipped with a mixer. The constant height storage tank is connected to the water distribution network of the city through a pipe and its water level is kept constant by a floater.

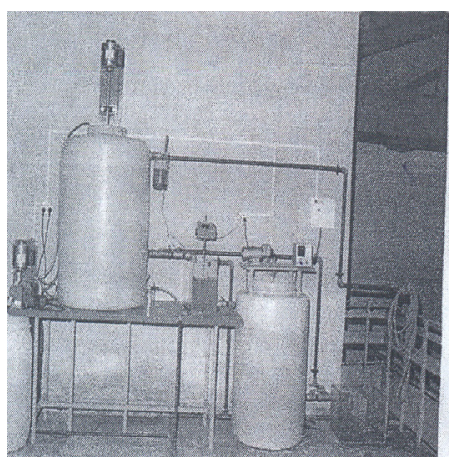

(a)

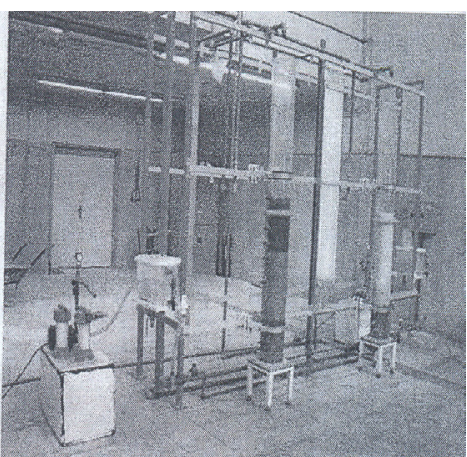

(b)

Figure 1: The pilot plant used in the study (a) Raw water preparation, coagulation and flocculation units (b) filtration units

\subsection{Experimental procedure}

Solutions with clay mud (turbidity generator) are added to the tank in the required amount, through the dosing pumps, to provide raw water with the desired quality. The turbidity amount of the raw water, according to Cleasby's suggestion, is set between 12 to 16 NTU [11]; the raw water will then enter the rapid mixing unit. In this unit, after addition of five milligrams of ferric chloride in 20 seconds with the velocity gradient of $9001 / \mathrm{sec}$, coagulation proceeds and after flocculation in the flocculation unit, water is directed to the distribution tank which is equipped with two $30^{\circ}$ v-notch weirs. Each section of the divided flow is measured by a rota meter and enters one column of the filter. Columns of the filter were made of plexy glass with a diameter of $200 \mathrm{~mm}$ and a height of 2 $\mathrm{m}$. The wall effect was evaluated using both tracing test and an experiment conducted on an empty column.

On each column, seven polyethylene valves for sampling and seven manometer pipes to measure the head loss were installed. To manage the backwash, filters were equipped with water pumps and air blowers, each with 
sufficient flow to maintain complete fludization. The filters applied in the experiment were dual media, first sand and anthracite, second lika and sand: the characteristics are indicated in table 1.

Table 1: $\quad$ Characteristics of materials in filter media.

\begin{tabular}{|c|c|c|c|c|}
\hline Filter type & $\begin{array}{c}\text { Filter } \\
\text { media }\end{array}$ & $\begin{array}{c}\text { Specific gravity } \\
(\mathrm{gr} / \mathrm{cm})\end{array}$ & $\begin{array}{c}\text { Effective size } \\
(\mathrm{mm})\end{array}$ & $\begin{array}{c}\text { Layer depth } \\
(\mathrm{m})\end{array}$ \\
\hline \multirow{2}{*}{$\begin{array}{c}\text { Dual } \\
\text { media }\end{array}$} & Silica sand & 2.62 & 0.60 & 0.35 \\
\cline { 2 - 5 } & Anthracite & 1.60 & 1.16 & 0.40 \\
\hline \multirow{2}{*}{$\begin{array}{c}\text { Dual } \\
\text { media }\end{array}$} & Silica sand & 2.62 & 0.60 & 0.35 \\
\cline { 2 - 5 } & lika & 1.5 & 1.08 & 0.40 \\
\hline
\end{tabular}

It is worth saying that in order to keep the stratification in media filter after its backwash, the fluidization velocity rate of all three layers should be the same. Therefore, using equation 1, knowing the specific gravity of the desired materials and selecting the diameter of the sand, diameters of other materials could be calculated [12].

$$
\frac{d_{1}}{d_{2}}=\left(\frac{\rho_{2}-\rho_{w}}{\rho_{1}-\rho_{w}}\right)^{0.667}
$$

In this equation $d_{1}$ and $d_{2}$ are diameters of materials and $p_{1}$ and $p_{2}$ are specific gravities of different type materials and $p_{\mathrm{w}}$ is the specific gravity of water. In order to control the filtration rate in the exiting current, a box with a floater in it is installed. In order to evaluate the effect of three of the most practical operational parameters on particle size and particle count of the effluent, the experiments were done under 6 different situations, first with different rates of the inlet and then different dosages of coagulant. The particle size and particle count was tested with a turbidity meter and particle size analyzer periodically every five minutes during the entire time of a filter run until the filter is saturated and has to go under backwash. The different experiments are shown in table 2.

\section{Table 2: $\quad$ Experiments.}

\begin{tabular}{|c|c|c|c|c|c|}
\hline Filtration rate & \multicolumn{2}{|c|}{$15 \mathrm{~m} / \mathrm{hr}$} & \multicolumn{3}{c|}{$5 \mathrm{~m} / \mathrm{hr}$} \\
\hline Coagulant dosage & $0 \mathrm{mg} / \mathrm{lit}$ & $8 \mathrm{mg} / \mathrm{lit}$ & $15 \mathrm{mg} / \mathrm{lit}$ & $0 \mathrm{mg} / \mathrm{lit}$ & $15 \mathrm{mg} / \mathrm{lit}$ \\
\hline Filter media & \multicolumn{2}{|c|}{ Sand -Anthracite } & \multicolumn{3}{c|}{ Sand- lika } \\
\hline
\end{tabular}

\subsection{Analytical methods}

The turbidity of the samples was measured with a turbidity meter (Hach model 2100N). Particle analyzing was performed using a particle counter (SHIMADZOU liquid Analyzer for turbidity and Size LATS-1) with effective size range $0.5-50$ micron $\mu \mathrm{m}$. 


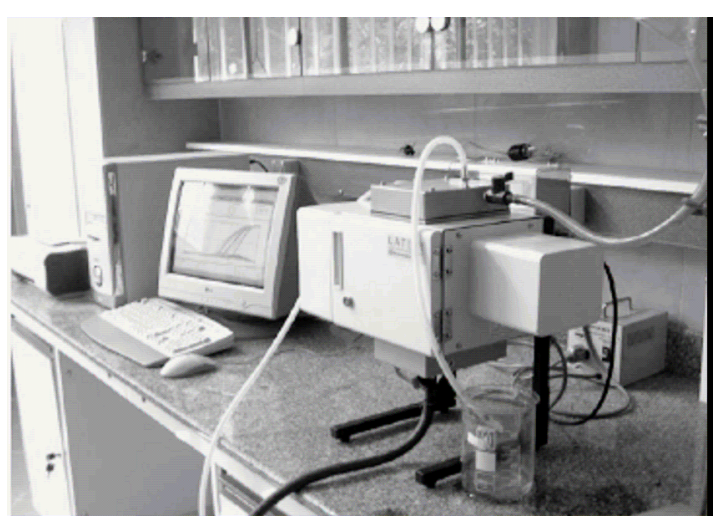

Figure 2: $\quad$ Particle size analyzer.

\section{Results and discussions}

The total summation of particles with the size of 2-10 micron was used as a parameter to indicate the quality. During the period of a filter run, this parameter vs. time was illustrated, since the filter media was one of the parameter, figure 3 is for the filter with lika media and figure 4 is for anthracite media. Each experiment was done at least 3 times and the regulation of them was selected. The optimized situation was evaluated by jar test and the best dosage was $8 \mathrm{mg} / \mathrm{l}$ and the best Filtration rate was $5 \mathrm{~m} / \mathrm{hr}$. The other parameters were to have a comparison with the optimized situation.

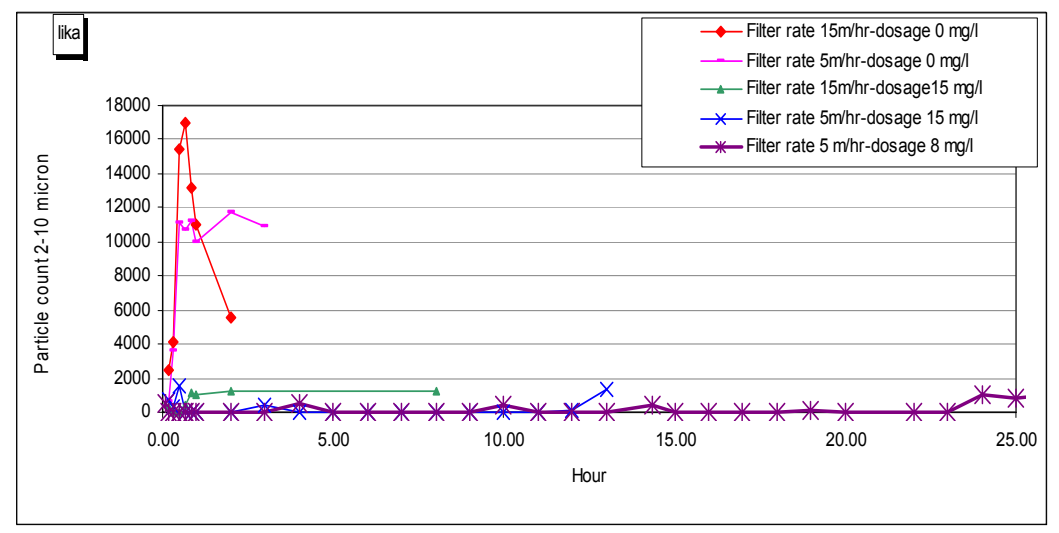

Figure 3: Particle count of particles with 2-10 micron in 5 different experiments during the filter run with Lika as the filter media.

As shown in figures 3 and 4, when the dosage of coagulant is reduced sedimentation on the filter media reduces and causes the removal procedure of particles to decrease leading to a poorer quality. However, increasing the 
filtration rate reduces the run time of the filter. To optimize the statistic equations and in order to have a better comparison of the total particles during the entire run of the filter, it was regulated and compared in figure 5.

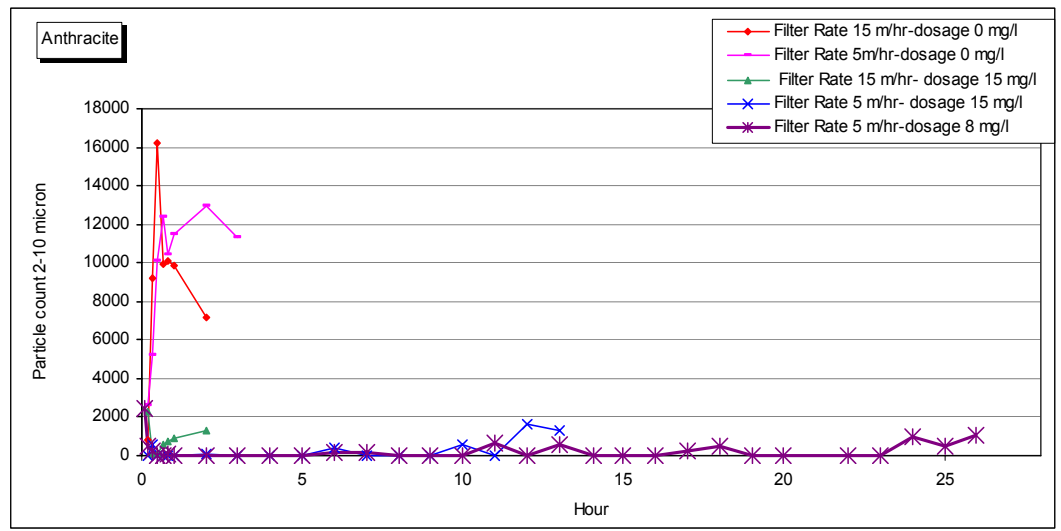

Figure 4: Particle count of particles with 2-10 micron in 5 different Experiments during the filter run with Anthracite as the filter media.

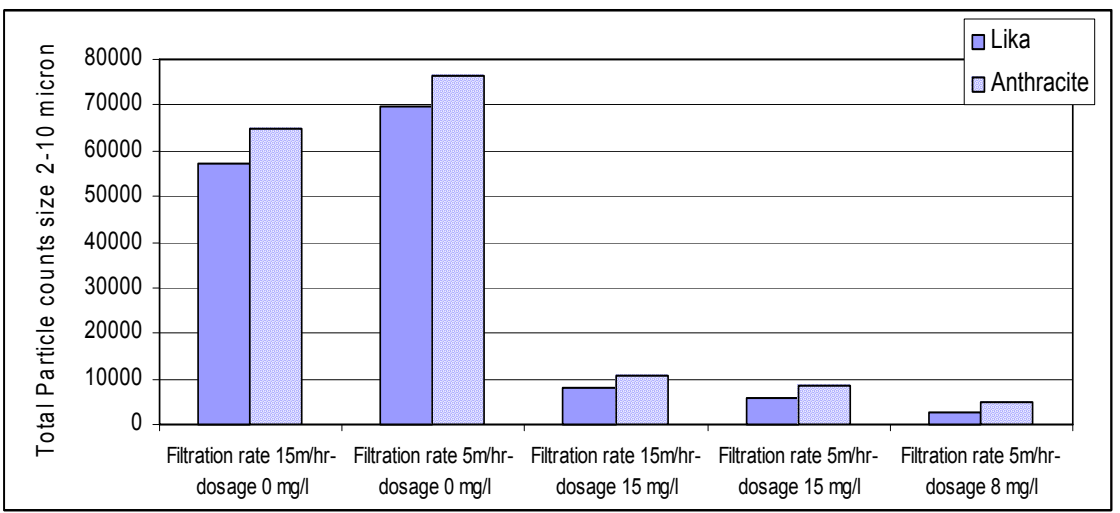

Figure 5: Total particle count of particles with 2-10 micron in 5 different experiments during the filter run with two media.

In ordinary situations during the first five to 20 minutes of the run of filter we suspect high turbidity and, indeed, high particle counts, but because the range of microorganisms is (4-10) micron for Giardia and (2-4) micron for Cryptosporidium [13], the main focus is on the total particle counts with a size of (2-10) micron which is a range that covers the presence of the cysts.

Invariable, filtration rates and coagulant dosages the experiments were done and it was clearly obvious that Lika as the filter media had a better effect than 
Table 3: $\quad$ Comparison of the effect of coagulant dosage and Filtration rate on the total particle count with the size of 2-10 micron on the effluent.

\begin{tabular}{|l|c|c|c|c|c|}
\hline Filtration rate & \multicolumn{3}{|c|}{$5 \mathrm{~m} / \mathrm{hr}$} & \multicolumn{2}{c|}{$15 \mathrm{~m} / \mathrm{hr}$} \\
\hline Coagulant dosage & $\begin{array}{c}0 \\
\mathrm{mg} / 1\end{array}$ & $88 \mathrm{mg} / 1$ & $15 \mathrm{mg} / 1$ & $\begin{array}{c}0 \\
\mathrm{mg} / 1\end{array}$ & $15 \mathrm{mg} / 1$ \\
\hline $\begin{array}{l}\text { Particle counts the effluent } \\
\text { with Anthracite as filter } \\
\text { media }\end{array}$ & 76,494 & 4,700 & 8,300 & 64,866 & 10,600 \\
\hline $\begin{array}{l}\text { Particle counts in the } \\
\text { effluent with lika as filter } \\
\text { media }\end{array}$ & 69,926 & 2,600 & 6,000 & 57,300 & 8,000 \\
\hline
\end{tabular}

anthracites. This result could be due to the effective size of it, and also it was investigated that the dosage of coagulant more than the sufficient dosage from jar test caused the immediate plugging but the effect could be softened by reducing the filtration rate. However, dosage had a stronger effect on the effluent particles than the filtration rate as indicated in table 3, with the same dosage of coagulant and different filtration rates, the diversion was more. When no coagulant is used the effluent goes under straight straining and no sedimentation is done so the total particles are more. On the other hand when the filtration rate is higher than the estimated one there is no time for the particles to settle on the media and we still see high particle counts.

\section{Conclusion}

Particle counting provides a precise and vital tool that extends water plant particulate monitoring and analysis to levels far beyond those afforded by turbidity alone [14].

Coagulant dosage has a very strong effect on filter effluent particle counts. Filtration rate is the second most important, with coagulant and media in third place.

In knowing the more effective operational parameter on the effluent we can use it to reduce our cost in treatment plants and also optimize the quality of the effluent.

\section{References}

[1] R.L. Chapman \& F. Fiessinger, Treatment process selection, pp. 2-4.

[2] A. Torabian, Pre ozonation and Pre chlorination effect on TOC removal in surface water treatment (2007).

[3] Michelle Colwell, Using particle counters to optimise water treatment plant filtration performance, $63^{\text {rd }}$ Annual Water Industry Engineers and Operator's Conference. 
[4] Murray B.A. (1995), Particle counting in water treatment (ch. 22), pp.3740.

[5] Anon (1996), Australian Drinking water guidelines and Armcanz common wealth of Australia.

[6] L. Trimboli (2001), Original of particles in filtered water, University of Massachusetts.

[7] Erica E. Hargesheimer \& Carrie M. Lewis, Particle counting How Why Where \& What equipment, Alberta water and waste water operators association.

[8] Lechevallier \& Norton (1992), Examining Relationship between Particle counts and Giardia cryptosporidium and turbidity, Journal AWWA 84(12): 54-60.

[9] Hargesheimer E.E. and C.M. Lewis (1995), A practical to an online Particle counting, Denver, CO; AWWA research foundation.

[10] Patania N.L., J.G. Jacangelo, L. Cummings, A.Wilczak, K. Riley and J. Oppenheimer. 1995. Optimization of filtration for cyst removal. Denver, CO; AWWA Research foundation.

[11] Cleasby, J.L. Is velocity gradient a valid turbulent flocculation parameter. Journal of Environmental Engineering, 110, 875-897 (1984).

[12] Qasim, S.R., Motely Guang Zhu, (2004), Water Works Engineering New Delhi.

[13] www.microbiology.com

[14] J. Daily, Use of Particle counters for measuring water treatment plant performance. 